\title{
Perfil da vítima de estupro em cidades de pequeno porte do Estado de São Paulo*
}

\author{
Wandercy BERGAMO' ${ }^{1}$, Luiz Henrique GEBRIM², Marcos de ALMEIDA ${ }^{3}$
}

Bergamo, W.; Gebrim, L.H.; Almeida, M. Perfil da vítima de estupro em cidades de pequeno porte do Estado de São Paulo. Saúde, Ética \& Justiça, 4(1/2):7-18, 1999.

Resumo: A proposta deste estudo foi, uma investigação das vítimas de estupro em cidades de pequeno porte do Estado de São Paulo. Foi desenvolvida uma pesquisa sobre estupro, no Instituto Médico Legal de Piraju-SP, no período de julho de 1994 a julho de 1997 (três anos), com 62 mulheres submetidas a perícia sexológica para conjunção carnal. A faixa etária das periciadas variou entre 4 e 54 anos (média de 13,8 anos), sendo que a maioria $(87,1 \%$ ) possuía idade inferior a 18 anos. Das 62 periciadas, 95,1\% eram solteiras. A cor predominante foi a branca com $87,1 \%$ e, a estudante foi a vítima mais freqüente com $59,7 \%$. O intervalo entre a "queixa" e a perícia, variou de exames realizados no mesmo dia a meses após, sendo que, 74,3\% foram examinadas antes de 15 dias entre a possível conjunção carnal e a perícia. De todas as periciadas, 37,1\% apresentavam hímen íntegro, 45,2\% apresentavam rotura himenal não recente, $4,8 \%$ hímen complacente e $12,9 \%$ apresentavam rotura himenal recente. A comprovação da conjunção carnal ocorreu em $25,8 \%$, sendo utilizados na perícia, a pesquisa dos três sinais de certeza de conjunção carnal (rotura himenal recente, presença de espermatozóides no canal vaginal e gravidez). Entre os casos de conjunção carnal positiva, a gravidez foi diagnosticada em $37,5 \%$ (9,6\% de todas as periciadas). A pesquisa de espermatozóides no canal vaginal resultou positiva em $9,7 \%$. De todas a periciadas, os agentes agressores acusados $64,5 \%$ foram "não parentes" e, 35,5\% parentes da vítima. Entre os parentes, o pai foi o agente agressor acusado em $41,0 \%$ dos casos. Observou-se que $58,1 \%$ das periciadas tinham idade entre 11 e 17 anos, o que vem comprovar que a vítima de estupro no interior é regra geral estudante e adolescente.

Unitermos: Estupro/psicologia. Violência. Medicina legal. Violência doméstica. Vítimas de crime/psicologia.

\section{Introdução}

$\mathrm{D}$ o latim "STUPRUM", quer dizer violar, desonrar. Consiste em constranger a mulher de qualquer idade ou condição à conjunção carnal por meio de violência ou grave ameaça $a^{1,2,10,11,12,13,18,19,22,29}$. Constranger significa violentar, coagir, impedir os movimentos, obrigar por força a fazer o que não se quer ${ }^{11,12,28}$. Só a mulher pode ser vítima dessa espécie delituosa, da mesma forma que somente o homem pode ser sujeito ativo da violência do estupro $0^{1,2,10,11,12,13,18,29}$. Mesmo sendo a mulher uma prostituta, ela tem o direito de dispor do seu próprio corpo e caso a

\footnotetext{
* Apresentado originalmente como Dissertação de mestrado à Escola Paulista de Medicina, Universidade Federal de São Paulo, em 1998.

1 Médico Legista. Mestre em Ginecologia pela Universidade Federal de São Paulo. Escola Paulista de Medicina.

2 Professor Adjunto da Disciplina de Ginecologia da Universidade Federal de São Paulo. Escola Paulista de Medicina.

${ }^{3}$ Professor Titular de Medicina Legal e Bioética da Universidade Federal de São Paulo. Escola Paulista de Medicina.

Endereço para correspondência: Rua João Hailer, 827. 18.800-000. Piraju, SP. E-mail: Wandercy@ourinhos.com.br
} 
Bergamo, W. et al. Perfil da vítima de estupro em cidades de pequeno porte do Estado de São Paulo.

conjunção carnal seja obtida mediante violência ou grave ameaça, continua a ter o rótulo de estupro $^{12}$. Constitui conjunção carnal o ato sexual normal, isto é, a cópula vaginal, sendo que outras modalidades de contato sexual não configuram o estupro, como a introdução do dedo ou de um objeto na cavidade vaginal; é investigada pelo exame do introito vaginal e hímen da periciada, pela pesquisa de espermatozóides no canal vaginal e pela presença de gravidez ${ }^{1,2,7,10,11,1213,15,18,19,22,29}$. No Brasil, não existem dados apropriados a respeito de sua incidência, porque os números que chegam às Delegacias são inferiores aos que ocorrem na realidade ${ }^{14,22}$.

\section{Objetivo}

O objetivo de nosso estudo foi avaliar o perfil da vítima de estupro em cidades de pequeno porte do interior do Estado de São Paulo, através dos dados coletados quanto à idade, cor, estado civil, ocupação, grau de escolaridade, intervalo decorrido entre a possível violência e a perícia, positividade da conjunção carnal e distribuição dos agressores acusados quanto ao tipo de parentesco com a vítima.

\section{Casuística e Método}

A pesquisa foi conduzida no Instituto Médico Legal de Piraju - SP, com uma área de abrangência de seis municípios com as mesmas características sócio econômico e culturais, totalizando uma população de 69.000 habitantes, estimada pelo I.B.G.E. no ano de 1996. Trata-se de uma região bastante pobre do Estado de São
Paulo, onde predomina a atividade agropecuária. Realizou-se o levantamento de laudos periciais de 62 mulheres submetidas à Exame de Conjunção Carnal com "queixa" de estupro, por nós examinadas no Instituto Médico Legal de Piraju, durante um período de três anos, de 1 de julho de 1994 a 1 de julho de 1997. Todas as pacientes foram examinadas seguindo-se um padrão. Constava da identificação, estado civil, idade, cor, ocupação, escolaridade, intervalo entre a possível violência e o exame, motivo do exame, histórico, função menstrual, presença de rotura himenal, presença de fluido seminal no canal vaginal, presença de gravidez, presença de outras lesões vaginais, exame das mamas, ânus, presença de outras lesões corporais, tipo de afinidade entre a vítima e o agressor acusado e outros dados como alcoolismo, uso de drogas, etc. A conclusão da existência ou não da conjunção carnal obedeceu aos sinais de certeza, pesquisados em todos os casos (rotura recente do hímen, pesquisa de espermatozóides no canal vaginal e/ou gravidez. O critério para a afirmação de rotura himenal recente foi a inspeção do hímen sendo que, nos casos duvidosos, utilizamos a colposcopia. Aqui, consideramos como hímens complacentes aqueles hímens com bastante elasticidade, exibindo ou não entalhes, e que não apresentavam à inspeção ou à colposcopia sinais de rotura. Em nosso serviço não temos possibilidade de pesquisar a fosfatase ácida; por isso colhemos material do canal vaginal com uso de cotonetes, transferindo o material para uma solução de soro fisiológico, o qual foi transferido para uma lâmina de microscópio e, entre lâmina e lamínula, a fresco, pesquisamos a existência de espermatozóides. A 
Bergamo, W. et al. Perfil da vítima de estupro em cidades de pequeno porte do Estado de São Paulo.

presença de um espermatozóide foi considerada positiva. A existência de gravidez foi confirmada por teste de urina (Pregnosticon Planotest) e por ultrassom obstétrico. Também procuramos verificar a existência de possíveis doenças sexualmente transmissíveis encaminhando-as para o Serviço de D.S.T. da Unidade de Saúde local para exames, inclusive testes para HIV.

\section{Resultados}

Os resultados são apresentados através de tabelas, de acordo com a distribuição dos casos segundo a positividade da conjunção carnal, idade, cor, estado civil, ocupação, grau de escolaridade, intervalo entre a possível violência e a perícia, rotura himenal, pesquisa de espermatozóides, sinais dignósticos de certeza, distribuição dos agentes agressores e parentesco dos acusados pelas vítimas.

Tabela 1 - Positividade da conjunção carnal entre as periciadas

\begin{tabular}{l|c|c}
\hline Conjunção Carnal & $\mathrm{N}^{\circ}$ & $\%$ \\
\hline \hline Sim & 16 & 25,8 \\
Não & 23 & 37,1 \\
Resposta Prejudicada & 23 & 37,1 \\
\hline Total & 62 & 100,0 \\
\hline
\end{tabular}

Tabela 2 - Distribuição das vítimas de acordo com a idade

\begin{tabular}{l|l|l}
\hline Idade (anos) & $\mathrm{N}^{\circ}$ & $(\%)$ \\
\hline \hline 4 a 10 & 18 & 29,0 \\
11 a 17 & 36 & 58,1 \\
18 ou mais & 08 & 12,9 \\
\hline Total & 62 & 100,0 \\
\hline
\end{tabular}

Tabela 3 - Distribuição das vítimas de acordo com a cor

\begin{tabular}{l|c|c}
\hline Cor & $\mathrm{N}^{\circ}$ & $(\%)$ \\
\hline \hline Branca & 54 & 87,1 \\
Mestiça & 07 & 11,3 \\
Negra & 01 & 1,6 \\
\hline Total & 62 & 100,0 \\
\hline
\end{tabular}

Tabela 4 - Distribuição das vítimas de acordo com o estado civil

\begin{tabular}{l|c|c}
\hline Estado Civil & $\mathrm{N}^{\circ}$ & $(\%)$ \\
\hline \hline Solteira & 59 & 95,1 \\
\hline Casada & 03 & 4,9 \\
\hline Total & 62 & 100,0 \\
\hline
\end{tabular}

Tabela 5 - Distribuição das vítimas de acordo com a ocupação

\begin{tabular}{l|r|r}
\hline Ocupação & $N^{\circ}$ & $(\%)$ \\
\hline \hline Estudante & 37 & 59,7 \\
Prendas domésticas & 11 & 17,7 \\
Sem ocupação & 06 & 9,7 \\
Trabalhadoras Rurais & 03 & 4,8 \\
Outras & 05 & 8,1 \\
\hline Total & 62 & 100,0 \\
\hline
\end{tabular}

Tabela 6 - Distribuição das vítimas de acordo com o grau de escolaridade

\begin{tabular}{l|c|c}
\hline Grau de escolaridade & $\mathrm{N}^{\circ}$ & $(\%)$ \\
\hline \hline I grau incompleto & 538 & 5,6 \\
I grau completo & 01 & 1,6 \\
Sem escolaridade & 04 & 6,4 \\
Menor de 7 anos & 04 & 6,4 \\
\hline Total & 62 & 100,0 \\
\hline
\end{tabular}


Bergamo, W. et al. Perfil da vítima de estupro em cidades de pequeno porte do Estado de São Paulo.

Tabela 7 -Distribuição das vítimas de acordo com o intervalo de tempo entre a possível violência e a perícia

\begin{tabular}{l|r|r}
\hline Tempo & $\mathrm{N}^{\circ}$ & $(\%)$ \\
\hline \hline Inferior a 24 horas & 28 & 45,2 \\
De 1 a 7 dias & 14 & 22,6 \\
De 8 a 15 dias & 04 & 6,5 \\
Após 15 dias & 13 & 20,9 \\
Ignorado & 03 & 4,8 \\
\hline & & \\
Total & 62 & 100,0 \\
\hline
\end{tabular}

Tabela 8 - Distribuição das vítimas de acordo com rotura himenal

\begin{tabular}{l|c|c}
\hline Rotura & $\mathrm{N}^{\circ}$ & $(\%)$ \\
\hline \hline Ausente & 23 & 37,1 \\
Não Recente & 28 & 45,2 \\
Recente & 08 & 12,9 \\
Hímen Complacente & 03 & 4,8 \\
\hline Total & 62 & 100,0 \\
\hline
\end{tabular}

Tabela 9 - Distribuição das vítimas de acordo com a pesquisa de espermatozóides no canal vaginal

\begin{tabular}{l|l|l}
\hline Pesquisa & $\mathrm{N}^{\circ}$ & $(\%)$ \\
\hline \hline Positiva & 06 & 9,7 \\
Negativa & 25 & 40,3 \\
Não realizada & 31 & 50,0 \\
\hline Total & 62 & 100,0 \\
\hline
\end{tabular}

Tabela 10 - Distribuição das vítimas com conjunção carnal positiva de acordo com o sinal diagnóstico de certeza

\begin{tabular}{l|c|c}
\hline Conjunção Carnal & $\mathrm{N}^{\circ}$ & $(\%)$ \\
\hline \hline Rotura Himenal Recente & 04 & 25,0 \\
Rotura Himenal Recente + & 04 & 25,0 \\
esperma vaginal & 06 & 37,5 \\
Gravidez & 02 & 12,5 \\
Esperma no canal Vaginal & 16 & 100,0 \\
\hline Total & 16 \\
\hline
\end{tabular}

Tabela 11 - Distribuição dos agentes agressores acusados quanto ao parentesco com as periciadas

\begin{tabular}{l|c|c}
\hline Parente & $\mathrm{N}^{\circ}$ & $(\%)$ \\
\hline \hline Sim & 22 & 35,5 \\
Não & 40 & 64,5 \\
\hline Total & 62 & 100,0 \\
\hline
\end{tabular}

Tabela 12 - Parentesco dos acusados pelas vítimas

\begin{tabular}{l|l|r}
\hline Parentesco & $\mathrm{N}^{\circ}$ & $(\%)$ \\
\hline \hline Pai & 09 & 41,0 \\
Tio & 04 & 18,2 \\
Padrasto & 02 & 9,1 \\
Irmão & 02 & 9,1 \\
Cunhado & 02 & 9,1 \\
Primo & 01 & 4,5 \\
Genro e primo & 01 & 4,5 \\
Marido & 01 & 4,5 \\
\hline Total & 22 & 100,0 \\
\hline
\end{tabular}

\section{Discussão}

Nossos estudos confirmaram e reforçaram algumas constatações em relação ao estupro e também revelaram alguns aspectos desta violência sexual em cidades de pequeno porte como a nossa região. Com relação à positividade da conjunção carnal, a análise da Tabela 1 mostrou $25,8 \%$ (16 casos) de positividade entre as 62 periciadas. Essa incidência foi superior à registrada no Instituto Médico Legal de Recife ${ }^{20}$, São Paulo ${ }^{9}$ e Belo Horizonte ${ }^{7}$, que registraram respectivamente $18,5 \%, 18,4 \%$ e $4,1 \%$ de positividade para conjunção carnal nas vítimas que fizeram queixa de estupro e semelhante aos achados de Salinas Portillo ${ }^{23}$ no Instituto Médico Legal de Santiago do Chile e Seabra \& 
Bergamo, W. et al. Perfil da vítima de estupro em cidades de pequeno porte do Estado de São Paulo.

Nascimento ${ }^{24}$ no Instituto médico Legal de Belém do Pará, que a registraram, respectivamente, em $23 \%$ e $26,4 \%$. A positividade da perícia guarda relação direta com a dificuldade de se colher dados seja por limitações técnicas, seja por desconhecimento da vítima ao comparecer tardiamente para a perícia, quando então as principais evidências já se perderam, tais como a presença de espermatozóides no canal vaginal e o desaparecimento de outras lesões genitais ou extra-genitais de violência. Acreditamos que a maior porcentagem de conjunção carnal positiva em nossos casos tenha ocorrido devido à freqüência mais elevada $(45,2 \%)$ de exames periciais nas primeiras 24 horas e mesmo no período inferior a 15 dias em relação à "queixa" com $74,3 \%$ das 62 periciadas (Tabela 7 ) e também pelo fato da perícia ser realizada por ginecologista, que tem melhor formação para a avaliação de rotura himenal. É muito difícil estabelecer a incidência real de estupro seja entre nós ou nos outros países porque os números que chegam às Delegacias são inferiores aos que ocorrem na realidade. Em nossa população a incidência de estupro foi de 0,15 casos em mil, o que é um dado bem inferior ao encontrado nos grandes centros ou no exterior. Acreditamos que o vexame, pudor, humilhação, trauma físico e/ou psíquico, receio de interpretações dúbias e receio de conhecimento pela população sejam motivos importantes para que a vítima deixe de declarar a queixa, e isto tudo torna-se muito mais evidente em cidades de pequeno porte, onde o conhecimento da vítima pela comunidade é muito grande. Conforme dados cedidos pelo Conselho Estadual da Condição Feminina da Secretaria do Governo do Estado de
São Paulo, de 1985 a 1990 pode-se encontrar incidência média de estupro de 2,0\% entre todos os Boletins de ocorrência das Delegacias de Polícia da Defesa da Mulher ${ }^{22}$. Quiñonez et al., ${ }^{21}$ em Santo Domingo, República Dominicana, referem ser de 1,7\% a incidência de estupro. Koss $^{16}$ et al. nos Estados Unidos, encontraram incidência e tentativa de estupro de 8,3\% entre estudantes. Bain \& Brown ${ }^{4}$ em um questionário distribuído aos adolescentes esperando por cuidados na Clínica Geral de Saúde dos Adolescentes, em Columbus (Ohio), entre junho a agosto de 1993 , referiram incidência de $16 \%$. Os resultados referidos pelos autores nacionais e estrangeiros são, portanto, muito discordantes uns dos outros. Pela análise da Tabela 2 vimos que $29,0 \%$ das periciadas tinham idade entre 4 e 10 anos; $58,1 \%$ entre 11 e 17 anos e 12,9\% tinham idade superior a 18 anos. Portanto, 87,1\% apresentavam idade inferior a 18 anos (menor, portanto, do ponto de vista penal). A incidência de $87,1 \%$ de mulheres com idade inferior a 18 anos foi um pouco superior à encontrada por Cohen \& Matsuda ${ }^{9}$ e Campos et al., ${ }^{7}$ que registraram respectivamente $72,3 \%$ e $79,4 \%$. A prevalência da vitimização ocorreu numa faixa etária de 4 a 54 anos, com média de idade de 13,8 anos, apresentando, a mais jovem, 4 anos de idade e, a mais idosa, 54. Assim, em relação à faixa etária, nossos achados confirmam que a maioria das vítimas que fazem queixa de estupro são menores de 18 anos, consideradas pelo nosso Código Civil incapazes. Julgamos que a nossa sociedade continua fazendo muito pouco para protegê-las. Observamos, também em nossos estudos, que $29,0 \%$ têm menos de 10 anos de idade, superior 
Bergamo, W. et al. Perfil da vítima de estupro em cidades de pequeno porte do Estado de São Paulo.

à referida por Cohen \& Matsuda ${ }^{9}$ e Campos et al. ${ }^{7}$, que relataram a freqüência de $19,5 \%$ e $8,2 \%$, respectivamente. São meninas impúberes, e a nosso ver ainda sem condições biológicas para a realização de um ato sexual. O agressor de uma vítima menor de 10 anos provavelmente demonstra um perfil psicopatológico diferente e, consequentemente, deveria ser visto de forma diferente pela nosso Código Penal. Por outro lado, observa-se que as vítimas maiores de 18 anos correspondem a apenas $12,9 \%$ e, ocorre uma diminuição à medida que a idade da mulher avança, o que nos leva a pensar que o amadurecimento da mulher permite-lhe melhor preservação, ao mesmo tempo que, com o avançar da idade, se torna menos vulnerável. Mas não podemos esquecer aqui, que, nessa idade, grande parte já possui vida sexual ativa, e assim, inúmeras vezes prefere não fazer "queixa" para não se submeter ao transtorno e vexame de se apresentar numa delegacia de polícia de cidade de pequeno porte onde ela é muito mais conhecida pela sociedade. Teixeira ${ }^{27}$ refere que a maioria das vítimas deixa de fazer queixas por motivos tais como vexame, pudor, humilhação; trauma físico e/ou psíquico, receio de doença venérea e de gravidez, receio de falta de compreensão e apoio ou interpretações dúbias da sociedade, receio de divulgação do caso pela imprensa, vexame com referência ao ambiente da queixa (Delegacia de Polícia e Instituto Médico Legal), temor de vingança por parte do(s) agente(s) e mesmo descrença nos resultados de ação das autoridades. Apesar de não haver uniformidade entre os autores na escolha dos termos para a descrição da cor e também haver grande variação de região para região, a análise da Tabela 3 mostrou que, em nossa região, houve maior freqüência da cor branca $(87,1 \%)$, ao contrário dos achados de Campos et al. ${ }^{7}$, onde a maior freqüência foi de mestiça com 59,2\%. Em nossa região predominou é a colonização italiana e espanhola donde o predomínio da cor branca. Em relação ao registro do estado civil, a Tabela 4 mostrou que, das 62 pacientes periciadas, $59 \mathrm{em}$ nosso estudo $(95,1 \%)$ eram solteiras e apenas 3 $(4,9 \%)$ eram casadas. A incidência de $95,1 \%$ de mulheres solteiras foi semelhante à de Campos $^{7}$ et al. que encontraram $91,3 \%$ de vítimas solteiras. O artigo 183, II do Código Civil estabelece como limite mínimo para o casamento, a idade de 16 anos para mulheres. Em nosso estudo, 49 das vítimas $(79,0 \%)$ estavam na faixa etária inferior a 16 anos. Aqui também pensamos que a mulher casada já tem mais maturidade, o suficiente para se preservar melhor, expondo-se menos aos riscos de uma agressão sexual. No tocante à ocupação das mulheres examinadas, a Tabela 5 mostrou uma percentagem significativa de estudantes $(59,7 \%)$, condizente com a faixa etária mais jovem, que é a vítima mais freqüente de estupro. Nossos dados estão de acordo com os estudos de Campos et al. ${ }^{7}$, em pesquisa sobre violência sexual no Instituto Médico Legal de Belo Horizonte, onde chamam a atenção para a porcentagem significativa de estudantes $(40,7 \%)$, também condizente com a faixa etária jovem. Em relação ao grau de escolaridade da vítima, a análise da Tabela 6 revelou percentagem significativa de vítimas com $1^{\circ}$ grau incompleto $(85,6 \%)$, também condizente com o fato da grande maioria das periciadas estarem na faixa etária 
Bergamo, W. et al. Perfil da vítima de estupro em cidades de pequeno porte do Estado de São Paulo.

média de 13,8 anos e de serem estudantes. Este aspecto é importante pois que, muitas vezes, a própria escola ou o próprio trajeto pode ser o local das agressões sexuais. Bagley et al. $^{3}$, em um estudo de entrevista de 1025 mulheres adolescentes em escolas secundárias de AlbertaCanadá, encontraram $23 \%$ delas que relataram a experiência de agressão sexual na escola pelo menos uma vez. Podemos concluir que a menor estudante, tendo que sair de casa para se locomover até a escola não só se expõe a um risco maior em seu trajeto lar- escola e vice-versa, como também fica exposta ao agressor masculino que também freqüenta a escola seja como estudante, seja como funcionário. Ao avaliar o tempo decorrido entre a violência e a perícia médica realizada, pudemos observar pela Tabela 7 que nossos casos apresentaram uma percen-tagem importante de $45,2 \%$ de "queixa" e exame nas primeiras 24 horas. Observamos também que $74,3 \%$ de vítimas foram examinadas com menos de 15 dias, o que, segundo a maioria dos autores, ainda permite com os recursos atuais a possibilidade diagnóstica de rotura himenal recente $\mathrm{e}^{1,9,11,12,18,19}$. No Instituto Médico Legal de São Paulo, com referência ao intervalo de dias entre a agressão e a perícia, $11,2 \%$ comparece-ram nas primeiras 24 horas; $44,7 \%$ de 1 a 7 dias; $8,0 \%$ de 8 a 15 dias e 30,2\% após 15 dias, portanto, 64\% foram examinadas antes de 15 dias $^{9}$. Acreditamos que não só na nossa região mas em outras mais desenvolvidas, como nos grandes centros e capitais, a mulher está ganhando o seu espaço, sentindo-se mais segura e confiante através da criação das Delegacias de Polícia de Defesa da Mulher, através dos movimentos feministas de esclarecimento e de proteção da mulher, estimulando a uma "queixa" mais precoce nas Delegacias de Polícia do que a tempos atrás. Apesar disso, achamos que o número de vítimas que comparecem nas primeiras 24 horas é baixo, tanto nas grandes como nas pequenas cidades, $e$ temos percebido que muito se preocupa com a constatação da agressão da vítima e pouca importância tem sido dada para a identificação do agressor, visto que enquanto nos países de primeiro mundo "KITS" especiais visando estes dois objetivos são usados de rotina, aqui os nossos Institutos Médico Legais carecem das necessidades mais elementares. Pelo estudo da Tabela 8 vemos que 23 entre as 62 periciadas $(37,1 \%)$ tinham ausência de rotura himenal; 28 $(45,2 \%)$ apresentaram rotura himenal não recente; $8(12,9 \%)$ rotura himenal recente e foram constatados $3(4,8 \%)$ hímens complacentes. Cohen \& Matsuda ${ }^{9}$ no Instituto Médico Legal de São Paulo, em 1987, relataram a percentagem de $44,6 \%$ de ausência de rotura himenal; $36,9 \%$ de rotura não recente e $18,4 \%$ de rotura recente, enquanto Campos et al. ${ }^{7}$, no Instituto Médico Legal de Belo Horizonte, em 1991, relataram freqüência de $50,6 \%$ de rotura himenal não recente e apenas $4,1 \%$ de rotura recente. Acreditamos que, em nossos casos, devido à importante percentagem $(45,2 \%)$ de periciadas nas primeiras 24 horas entre a agressão e a queixa e mesmo pela alta percentagem (74,3\%) examinada com intervalo de tempo menor que 15 dias após a agressão (Tabela 7), possibilitou o diagnóstico em maior número de casos. Slaughter et al. ${ }^{26}$, em San Luis Obispo na Califórnia, relatam $87 \%$ de achados positivos empregando a colposcopia em 131 vítimas de 
Bergamo, W. et al. Perfil da vítima de estupro em cidades de pequeno porte do Estado de São Paulo.

estupro, sendo as perícias realizadas dentro de 48 horas após a suposta agressão. No Brasil, Teixeira ${ }^{27}$ também demonstrou a importância do colposcópio para o diagnóstico diferencial entre roturas e entalhes, bem como para avaliar com maior exatidão o período de cicatrização das roturas himenais. Nos casos de hímen íntegro complacente, isto é, hímens que apesar da cópula não se rompem, é difícil a comprovação da conjunção carnal, a não ser quando encontramos esperma no canal vaginal, ou gravidez. Em relação à pesquisa de espermatozóides no canal vaginal daquelas periciadas que tinham indicação para este exame, o estudo da Tabela 9 nos mostrou que, de 31 pesquisas realizadas, 9,7\% foram positivas e $40,3 \%$ negativas. Nas outras 31 periciandas (50\%) não houve indicação para a pesquisa de esperma-tozóides. Consideramos esta percentagem como um avanço importante dado à escassez de registros na literatura nacional. Acreditamos que os serviços bem organizados, aliados ao maior esclarecimento das mulheres, como ocorre nos países de primeiro mundo, permitindo queixas e exames nos dias imediatamente subsequentes, revelarão, como conseqüência, alta percentagem na pesquisa de espermatozóides. Infelizmente, na maioria das vezes isto não acontece em nossos Institutos Médico Legais e, é óbvio, quanto maior o intervalo de tempo entre a "queixa" e o exame, menor a possibilidade de resultados positivos. Em relação à pesquisa de espermatozóides na cavidade vaginal, a positividade cai rapidamente, não sendo mais possível detectar após 72 horas, e no ânus só é possível encontrar nas primeiras 6 horas, pois os espermatozóides sofrem lise ou são eliminados 9 . O tempo de sobrevivência do espermatozóide é diminuído em garotas prépúberes, devido à falta de muco cervical ${ }^{24}$. Além disso, nem sempre a pesquisa de espermatozóides no canal vaginal das periciadas é realizada como rotina de serviço nos Institutos Médico Legais em nosso país. $O$ estudo da Tabela 10 mostrou que o diagnóstico de conjunção carnal em 8 dos 16 casos (50\%) foi possível pelo exame de rotura himenal recente. A gravidez ocorreu em $37,5 \%$ dos 16 casos positivos para conjunção carnal. Chamou a atenção em nossos casos não só a alta taxa de gravidez, como também o namorado como o agente acusado na maioria das conjunções carnais positivas em vítimas menores de 18 anos. Aqui cabe a elaboração de algumas hipóteses tais como: não seriam muitos desses casos na realidade crime de sedução, embora as vítimas tenham estabelecido queixa de estupro? Não teriam essas vítimas, de modo geral, procurado as Delegacias para suas "queixas", pessoalmente ou através de seus genitores ou responsáveis, porque o atraso menstrual, ou o estado adiantado da gravidez, chamou a atenção e desencadeou a queixa induzida pelos pais ou responsáveis da vítima? Ao estudarmos a distribuição dos agentes agressores acusados pelas vítimas, a Tabela 11 nos mostrou que 40 $(64,5 \%)$ foram não parentes contra $22(35,5 \%)$ parentes das periciadas. Cartwright ${ }^{8}$ relatou freqüência de $50 \%$ de agentes agressores sexuais estranhos à vítima. Seabra \& Nascimento ${ }^{24}$ referiram $41,3 \%$ de desconhecidos da vítima nas agressões sexuais na infância. A literatura refere que os parentes e pessoas de conhecimento das vítimas respondem pela maioria dos agentes 
Bergamo, W. et al. Perfil da vítima de estupro em cidades de pequeno porte do Estado de São Paulo.

agressores. Quando estudamos a incidência dos principais agentes agressores acusados entre os parentes, a Tabela 12 nos mostrou que, entre os 22 parentes, o pai foi o principal agente acusado em $41,0 \%$ dos casos, seguido do tio em $18,2 \%$. $\mathrm{Na}$ relação suspeito/vítima dos crimes sexuais contra menores de 14 anos no período de $1^{\circ}$ de novembro de 1995 a 30 de junho de 1996 na Delegacia de Proteção à Criança e ao Adolescente, o pai figurou em $8,7 \%$, seguido do padrasto com $6,5 \%$ e do namorado com $6,5 \%$, dos casos $^{24}$. Na Tabela 12 chama ainda a atenção pela sua aparente estranheza, um caso em que o agente agressor acusado é o próprio marido. Trata-se de um caso em que o marido, alcoolizado, utilizou-se de violência para manter a conjunção carnal com sua esposa. A vítima não só registrou queixa de estupro como foi hospitalizada em conseqüência a importante hemorragia vaginal devido ao traumatismo, necessitando de cuidados médico-hospitalares. Este fato não é incomum, pois tem sido relatado por diversos autores estrangeiros ${ }^{5,6,25}$. Observa-mos, ainda, que a maioria dos nossos casos ocorreram em classes sociais de baixa renda, onde predominava a ignorância, a pobre-za, a inadequada habitação e a promiscuidade. Portanto, para uma comprovação mais eficaz da conjunção carnal sugerimos que a população seja cada vez mais esclarecida sobre a importância da queixa imediatamente após a agressão sexual, para que os indícios não se desfaçam com o tempo. Também consideramos fundamental a melhoria dos recursos humanos e técnicos utilizadas na perícia médica para conjunção carnal, tais como a utilização de colposcópio, microscópio, o que infelizmente não estão disponíveis na grande maioria dos Institutos Médico Legais do Estado. Para a comprovação da penetração vaginal e correspondente coleta de provas foi criado um "KIT" especial, visando este objetivo, conhecido como "SEX CRIME LAB KIT", da autoria de Wilmes Roberto Gomes Teixeira ${ }^{28}$, que consiste em uma caixa contendo os seguintes materiais descartáveis: um espéculo vaginal, luvas, pente, "swab" (para a coleta das secreções - vagina, boca e reto), lâminas (esfregaços), raspador e cortador de unha, lupa, frasco para a coleta de sangue (tipagem) e urina (para teste de gravidez), envelopes ( para colocar aparas e resíduos de unhas, cabelos, pêlos, etc.), rótulos, inclusive para lacrar o "KIT" após o seu uso, além de protocolo impresso, que é o guia do exame para o médico ${ }^{27}$. A coleta de provas a que este "KIT" se destina diz respeito a pêlos pubianos, cabelos e aparas de unhas (eventualmente com micropartículas de sangue e fragmentos de pele do agente agressor), pesquisa de espermatozóides e dosagem de fosfatase ácida vaginal, determinação no sêmen de marcadores genéticos do agente e urina para o teste de gravidez. Quanto mais completa forem as provas mais ajudam a identificação, pela polícia, do agente agressor ${ }^{27}$. Também a pesquisa de Doenças Sexualmente Transmissíveis, incluindo a AIDS, deveria ser incrementada a fim de que a vítima pudesse ser convenientemente diagnosticada e orientada na busca de um tratamento adequado. No "The Sexual Assault Resource Service", em Dallas, programa que tem providenciado alto nível de assistência às vítimas de estupro, 412 vítimas realizaram testes para HIV três e seis meses após o estupro, não se 
Bergamo, W. et al. Perfil da vítima de estupro em cidades de pequeno porte do Estado de São Paulo.

registrando nenhum caso de soro-conversão positiva. Apesar do risco ser baixo, recomendase a realização dos testes para HIV três e seis meses após o estupro, especialmente se houve 0 coito anal ou se a vítima está inserida em grupo de risco ${ }^{17}$. Também pensamos que é difícil estabelecer, entre nós, a incidência do estupro em uma determinada localidade brasileira, devido à falta de centros de atendimento específico, conforme já o disse Halbe ${ }^{15}$. Não sendo uma violência de instalação obrigatória de investigação policial, os dados referentes aos casos com instalação de inquérito policial também não fornecem uma estatística da sua freqüência ${ }^{15}$. Halbe \& Vitielo ${ }^{14}$ relataram a ocorrência de 300 estupros por mês nessa época na cidade de São Paulo, sendo a chamada cifra cinzenta de 10 vezes maior, prendendo-se a razão sobretudo ao aumento da violência humana, recomendando que a mulher estuprada seja atendida pela polícia feminina e examinada por médica legista. Acreditamos que, atualmente, o estupro bem como todo o tipo de violência sexual seja muito maior do que antigamente. Ele ocorre não só nos grandes centros como avança para as cidades de pequeno porte assim como a violência em sua globalidade. Ainda que a mulher pudesse ser atendida exclusivamente pela polícia feminina e examinada por médica legista, a simples verificação do estupro não deixa de ser a continuação de uma violência já sofrida, visto ser necessária uma tramitação legal para apuração dos fatos. Existe, sem dúvida, a penalização para o agente agressor, mas não existe ainda uma profilaxia adequada contra esta violência sexual. Acreditamos que dificilmente uma mulher consegue impedir o estupro nos dias atuais, visto que sua reação pode lhe custar a vida. Além disso, a situação emocional da vítima é mais séria do que se imagina. Os nossos estudos apontam para uma evidente necessidade de alertar os profissionais de Saúde para que tomem consciência de que as agressões sexuais são um fenômeno importante, não apenas em freqüência. mas em termos biológicos e psicossociais. Não se trata de algo que acontece esporadicamente, ocorrendo com mais freqüência do que se imagina, mas que muitas vezes "escapa" à observação clínica, seja porque os profissionais não estão atentos, ou porque preferem fugir do assunto em face de suas próprias limitações. As autoridades devem ser alertadas para que os nossos Institutos Médico Legais mereçam uma maior atenção, dotando-os de melhores condições técnicas como colposcópio, microscópio e "KITS" adequados, a fim de que a perícia seja a mais completa possível. Quanto mais completas forem as provas, mais ajudarão na identificação, pela polícia, do agente agressor. Os profissionais médicos legistas devem ser alertados sobre os diversos aspectos biopsicosociais do estupro, a fim de que a perícia, obrigatória nos Institutos Médico Legais, não se torne mais uma violência à vítima já totalmente traumatizada e humilhada. Enfim, a classe médica e a sociedade como um todo devem participar de um processo de esclarecimento a fim que realmente possa haver uma diminuição dessa violência hedionda que atinge, em sua maioria, jovens meninas com idade cada vez mais decrescentes. A violência sexual e, com ela, o estupro não é apenas um problema da Medicina Legal e/ou do Direito, mas de interesse de toda a classe médica e da sociedade. 
Bergamo, W. et al. Perfil da vítima de estupro em cidades de pequeno porte do Estado de São Paulo.

\section{Conclusão}

Os dados coletados e analisados em nosso estudo, relativo ao perfil de vítima de estupro em cidades de pequeno porte do Estado de São Paulo apontaram:

1. mulher adolescente $(58,1 \%)$, na sua maioria com idade inferior a 18 anos (87,1\%), sendo a de menor idade 4 anos e a mais idosa 54 anos, com média de idade de 13,8 anos;

2. mulher de cor branca $(87,1 \%)$, solteira $(95,1 \%)$ e estudante $(59,7 \%)$;
3. cerca de $74,3 \%$ das vítimas foram examinadas em tempo inferior a 15 dias após a possível violência $(45,2 \%$ nas primeiras 24 horas e $29,1 \%$ entre 1 a 15 dias);

4. a positividade de encontro de conjunção carnal foi de $25,8 \%$;

5. a relação agente acusado/vítima indicou uma percentagem de $35,5 \%$ de parentes das vítimas e, destes, o pai figurou como 0 mais freqüente agente acusado em $41,0 \%$ dos casos.

Bergamo, W.; Gebrim, L.H.; Almeida, M. Characteristic of the rape victim is profile a town from São Paulo State. Saúde, Ética \& Justiça, 4(1/2):7-18, 1999.

\begin{abstract}
The proposal about this study was an investigation of rape victims in small town of São Paulo State. A research about rape in Piraju's Legal Medicine Institute was developed, with 62 women submitted to sexologic evaluation, from July 1994 to July 1997 (three years). The age varied from 4 to 54 years old (average 13,8) and most of them $(87,1 \%)$ was under 18 years old. It was observed that $95,1 \%$ women were single. The predominant color was white $(87,1 \%)$ and, the most usual victim was the student $(59,7 \%)$. The interval between the "complaint"and the examination varied, from examinations performed at the same day to months later, however $74,3 \%$ was performed less than 15 days after the possible rape. About all women submitted to sexologic evaluation, 37,1\% have intact hymen, $45,2 \%$ have non recent hymenal rupture and $12,9 \%$ have recent hymenal rupture. The intercourse was comproved in $25,8 \%$ using in the examination three certainty signs (recent hymenal rupture, sperm-cell from the vagina and pregnancy). Among these cases of positive intercourse, the pregnancy was diagnosed in $37,5 \%(9,6 \%$ of all women submitted to sexologic evaluation). The research of sperm-cell from the vagina was positive in $9,7 \%$. In all women submitted to examination, $64,5 \%$ of people without any relationship was accused, and victims'relatives was $35,5 \%$. Among the relatives of all the victims the accused was the father $41,0 \%$. It was observed that $58,1 \%$ of all women submitted to examination was from 11 to 17 years old, were student and teenager.
\end{abstract}

Keywords: Rape/psychology. Violence. Crime victims/psychology. Domestic violence.

\title{
Referências Bibliográficas
}

1. Almeida Junior, A. A prova pericial da conjunção carnal. In: Almeida Junior, A. Lições de medicina legal. 6.ed. São Paulo, Companhia Editora Nacional, 1962. p.290-304.

2. Arbenz, G.O. Aspectos médico legais da conjunção carnal. In: Arbenz, G.O. Medicina legal e antropologia forense. São Paulo, Atheneu, 1988. p.447-56.

3. Bagley, C.; Bolitho, F.; Bertrand, L. Sexual assault in school, mental health and suicidal behaviors in adolescent women in Canada. Adolescence, 32:361-6, 1997.

4. Bain, J.E.; Brown, R.T. Adolescents as witnesses to violence. J. Adolesc. Health, 19:83-5, 1996. 
Bergamo, W. et al. Perfil da vítima de estupro em cidades de pequeno porte do Estado de São Paulo.

5. Browne, A. Violence against women by male partners. Am. Psychol. Assoc., 48:1077-87, 1993.

6. Burge, S.K. Violence against women. Prim. Care, 24: 67-81, 1997.

7. Campos, J.R.; Nascimento, L.G.; Almeida Junior, W.J.; Vaintraub, M.C.; Silva, H.M.S.; Lopes, G.P. Violência Sexual em Belo Horizonte, Pesquisa no Instituto Médico Legal. J. Bras. Ginecol., 104:22730, 1994.

8. Cartwright, P.S. Violência Sexual. In: Jones, H.W.; Wentz, N.C.; Burnett, L.S. Novak's textbook of gynecology. 11.ed. Rio de Janeiro, Guanabara Koogan, 1990. p.384-90.

9. Cohen, C.; Matsuda, N.E. Crimes sexuais e sexologia forense: estudo analítico. Rev. Paul. Med., 109:157-64, 1991.

10. Croce, D.; Croce Júnior, D. Sexologia forense. In: Croce, D.; Croce Júnior, D. Manual de medicina legal. 3. ed. São Paulo, Saraiva, 1995. p.400-503.

11. Fávero, F. Sedução (defloramento). Estupro. In: Fávero, F. Medicina Legal. 12.ed. Belo Horizonte, Villa Rica, 1991. p.664-93.

12. França, G.V. Sexologia criminal. In: França, G.V. Medicina Legal. 4.ed. Rio de Janeiro, Guanabara Koogan, 1994. p.147-58.

13. Gomes, H. Sexualidade criminosa: sedução; estupro. In: Gomes, H. Medicina legal. 31.ed. São Paulo, Livraria Freitas Bastos, 1993. p.419-37.

14. Halbe, H.W.; Vitiello, N. Estupro. Femina, 11:460. 1983.

15. Halbe, H.W. Estupro. In: Halbe, H.W. Tratado de ginecologia. 2.ed. São Paulo, Rocca, 1987. p. 81927.

16. Koss, M.P.; Gidycs, C.A.; Wisniewski, N. The scope of rape: incidence and prevalence of sexual aggression and victimization in anational sample of higher education students. J. Consult. Clin. Psychol., 55:162-70, 1987.

17. Ledray, L.E. The sexual assault resource service: a new model of care. Minn. Med., 79:43-5, 1996.
18. Maranhão, O.R. Introdução à sexologia forense. In: Maranhão, O.R. Curso básico de medicina legal. 8. ed. São Paulo, Malheiros, 1996. p.127-243.

19. Mello, J.A. Sexologia forense: o estupro. In: Mello, J. A. Medicina legal. São Paulo, Fittipaldi, 1991. p.300-1.

20.Pinho-Neto, J.S.; Lima, J.C.; Macedo, L.R.S.; Figueiredo, V.R.; Souza, A.H.A.R. Dez anos de vitimização sexual em crianças da cidade de Recife: aspectos médico legais. Femina, 18:76875, 1990.

21. Quiñonez, E.M.; Luciano-Consuegra, A.M.; Marte, H.M.O.; Guillermo, J.P.; Durán-Almonte, M.; MontroMontero, R. Violación e intento de violación en una población de escolares femininos. Rev. Med. Domin., 54:21-3, 1993.

22. Rosa Lima, S.M.R. Estupro. In: Halbe, H.W. Tratado de ginecologia. 2.ed. São Paulo, Rocca, 1993. p.970-77.

23. Salinas-Portillo, H. Rol del pediatria frente a la violación. Rev. Pediatr., 26:122-4, 1983.

24. Seabra, A.S.; Nascimento, H.M. Abuso sexual na infância. Arq. Bras. Pediatr., 4:72-82, 1997.

25. Serra, P. Physical violence in the couple relationship: a contribution toward the analysis of the context. Fam. Process., 32: 21-33, 1993.

26. Slaughter, L.; Brown, C.R.V.; Crowley, S.; Peck, R. Patterns of genital injury in female sexual assault victims. Am. J. Obstet. Gynecol., 176:609-16, 1997.

27. Teixeira, W.R.G. Colposcopia himenal em perícias médico legais. (Mogi das Cruzes), 1977. Tese (Livre-docência ) - Faculdade de Medicina da Universidade de Mogi das Cruzes.

28. Teixeira, W.R.G. Kit para o exame de vítimas de estupro. Inf. Médico Legal, 14, 1986.

29. Veiga de Carvalho, H.; Segre, M.; Meira, A.R.; Almeida, M.; Salaru, R. N.N.; Munhoz, R.D.; Cohen, C. Compêndio de medicina legal. 2. impr. São Paulo, Saraiva, 1992. p. 285-328. 